05.1;06.4

\title{
Особенности нестационарной деформации при воздействии слабого магнитного поля
}

\author{
(C) В.В. Шпейзман \\ Физико-технический институт им. А.Ф. Иофффе РАН, Санкт-Петербург, Россия \\ E-mail: shpeizm.v@mail.ioffe.ru
}

Поступило в Редакцию 16 января 2020 г.

В окончательной редакции 19 февраля 2020 г.

Принято к публикации 23 марта 2020 г.

\begin{abstract}
Определены скорости деформации свинца при одноосном сжатии и постоянных напряжениях и температуре, а также характеристики скачков скорости в начальный период воздействия постоянного магнитного поля и сразу после прекращения его воздействия. Показано, что в этих областях после резкого изменения скорости имеется короткий участок возврата скорости деформации, который характеризуется увеличением разброса скорости, вызванного ее скачками, и расширением области размеров нанометровых скачков.
\end{abstract}

Ключевые слова: деформация, магнитное поле, скачки скорости деформации.

DOI: 10.21883/PJTF.2020.12.49521.18205

Влияние слабого по величине постоянного магнитного поля (ПМП) на характеристики деформации различных по своей природе и магнитным свойствам твердых тел изучается уже несколько десятилетий [1-9]. В качестве возможного механизма воздействия слабого магнитного поля на деформацию рассматривается его воздействие на различные виды точечных дефектов (электроны, дырки, примесные центры и др.). На основе теории спин-зависимых реакций между подвижными частицами и неспаренными электронами предложены модели сложных многоуровневых процессов, возникающих в твердом теле при воздействии магнитного поля на дефекты структуры. К исследованиям, выполненным на объектах мезоуровня, можно отнести изучение влияния ПМП на эффект Портевена-Ле Шателье в работе [10], в которой обнаружено уменьшение величины скачков деформации при действии ПМП. На кристаллах $\mathrm{NaCl}: \mathrm{Eu}$ при определенных концентрациях примеси авторы наблюдали скачкообразное пластическое течение, обусловленное динамическим старением дислокаций, т.е. образованием примесных облаков Коттрелла или Сноека вокруг ядер дислокаций. Этот процесс сопровождается кластеризацией изолированных примесно-вакансионных диполей, на которые непосредственно воздействует магнитное поле.

В большинстве экспериментальных работ по магнитопластическому эффекту (МПЭ) рассматривается только изменение макроскопических характеристик (скорости или силы сопротивления деформации, твердости, предела упругости и др.) под действием магнитного поля. Они подробно описаны в перечисленных выше обзорах $[2-4,6,7,9]$. Отдельно следует отметить недавние работы [11-13], в которых рассматривается МПЭ при релаксации напряжений в кристаллах $\mathrm{NaCl}$ [11] и влияние ПМП на микротвердость кристаллов дигидрофосфата калия $[12,13]$. Эффект разупрочнения ряда сплавов под действием ПМП нашел практическое применение при их механической обработке [14-16].

В ФТИ им. А.Ф. Иоффе работы по влиянию ПМП на различные характеристики деформации проводятся с позиции представления о деформации как о многоуровневом процессе, причем за уровень принимается величина скачка абсолютной деформации при одноосном нагружении образца. Благодаря развитой методике определения линейных перемещений с помощью лазерного интерферометра [17] и способам обработки результатов эксперимента [18] удалось наблюдать микро- и нанометровые скачки деформации и вызвавшие их скачки скорости деформации.

Малые скачки величины и скорости деформации, а также изменение характеристик скачков в ПМП обсуждаются в [18-23]. Для определения скорости и величины деформации в [18-23] была использована прецизионная интерферометрическая методика, позволяющая измерять скорость деформации по частоте биений на выходе интерферометра в пределах линейных перемещений до $\sim 300 \mathrm{~nm}$ [19-22], а при анализе формы биения - до нескольких нанометров [18,23]. Исследования, проведенные на ряде металлов и полимеров, показали, что магнитное поле приводит в большинстве случаев к небольшому росту средней скорости деформации и перераспределению вкладов в нее скачков разной величины. Введение магнитного поля при деформации образца приводило к кратковременному резкому возрастанию скорости деформации с последующим ее падением до величины, большей или близкой к той, что была при деформации без поля. При прекращении действия ПМП наблюдался обратный эффект. Величина стационарного МПЭ зависела от скорости деформации и величины действующих напряжений, и в некоторых случаях стационарный МПЭ отсутствовал. Нестационарный участок МПЭ наблюдался в наших опытах всегда. Настоящая ра- 


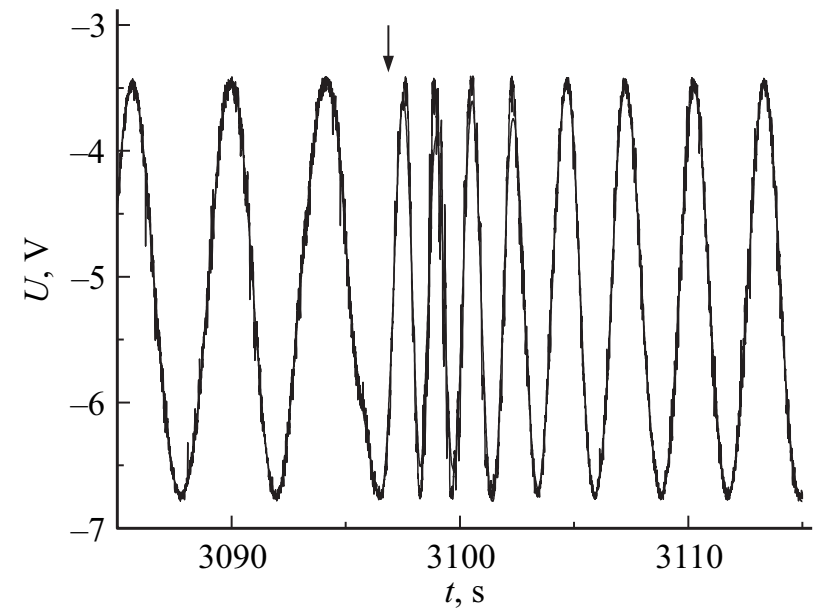

Рис. 1. Пример интерферограммы в момент перехода от деформации вне ПМП к деформации в ПМП. Стрелкой показан момент введения поля.

бота посвящена исследованию нестационарного участка деформации сразу после изменения условий деформации: в ПМП и без него.

Образцы свинца (99.98 wt.\%), представлявшие собой цилиндры высотой $6 \mathrm{~mm}$ и диаметром $4 \mathrm{~mm}$, подвергались одноосному сжатию при постоянном напряжении и комнатной температуре. Методика определения скорости деформации $\dot{\varepsilon}$ основана на измерении частоты низкочастотных биений, получаемых в результате интерференции луча, отраженного от зеркала, жестко связанного с нагружающим штоком испытательной машины, и опорного луча лазера. Под величиной скачка абсолютной деформации $L$ в микро- и нанометровом диапазонах понималось среднее расстояние (перемещение штока машины) между близкими по величине пиками (или группами пиков) зависимости скорости деформации от ее величины. При этом для скачков нанометрового диапазона рассматривались отклонения формы биения от результирующей синусоиды. Подробно методические вопросы рассмотрены в $[18,23]$. Магнитное поле с вектором магнитной индукции насыщения величиной $B=0.2 \mathrm{~T}$, направленным перпендикулярно оси образца, создавалось постоянным магнитом, перемещением которого можно было создавать магнитное поле в образце или удалять его за короткое (порядка 2-3 s) время.

На рис. 1 показан фрагмент интерферограммы, иллюстрирующий изменение скорости деформации (пропорциональной частоте биений) в области перехода к деформации в ПМП. Для исследования нестационарных участков деформации были проведены измерения скорости деформации с разрешением (изменением длины образца, на котором усредняется скорость деформации), равным $162.5 \mathrm{~nm}$, в то время как в [23] оно было в 2 раза больше. Результаты для одного из циклов перехода от деформации без ПМП к деформации в ПМП, а также обратного перехода представлены на рис. 2.
Нестационарный участок деформации в приведенном примере занимает $\sim 20$ s при введении поля и $\sim 110 \mathrm{~s}$ при его удалении. Граница в последнем случае определялась по положению максимума скорости (переходу к затуханию). Сравнение скоростей на стационарных участках деформации показывает, что в магнитном поле наблюдается ускорение деформации на $14-21 \%$ (соответственно от $1.17 \cdot 10^{-5}$ до $1.42 \cdot 10^{-5} \mathrm{~s}^{-1}$ в первом случае и от $1.26 \cdot 10^{-5}$ до $1.11 \cdot 10^{-5} \mathrm{~s}^{-1}$ во втором). После возврата деформации в первоначальные условия скорость оказалась несколько ниже, чем была ранее. Возможно, это связано с небольшим падением скорости деформации со временем, что характерно для испытаний с постоянным напряжением. Приведенное соотношение скорости деформации в ПМП и вне его следует рассматривать как характеристику условий деформации. В нашем случае оно зависело от времени и начальной скорости деформации и изменялось от 1 (отсутствие эффекта) до 1.4.

Как видно из рис. 2 , переходные участки различаются и по величине резкого изменения скорости деформации в начальный момент воздействия ПМП и после его отмены, а также по времени установления стационарного
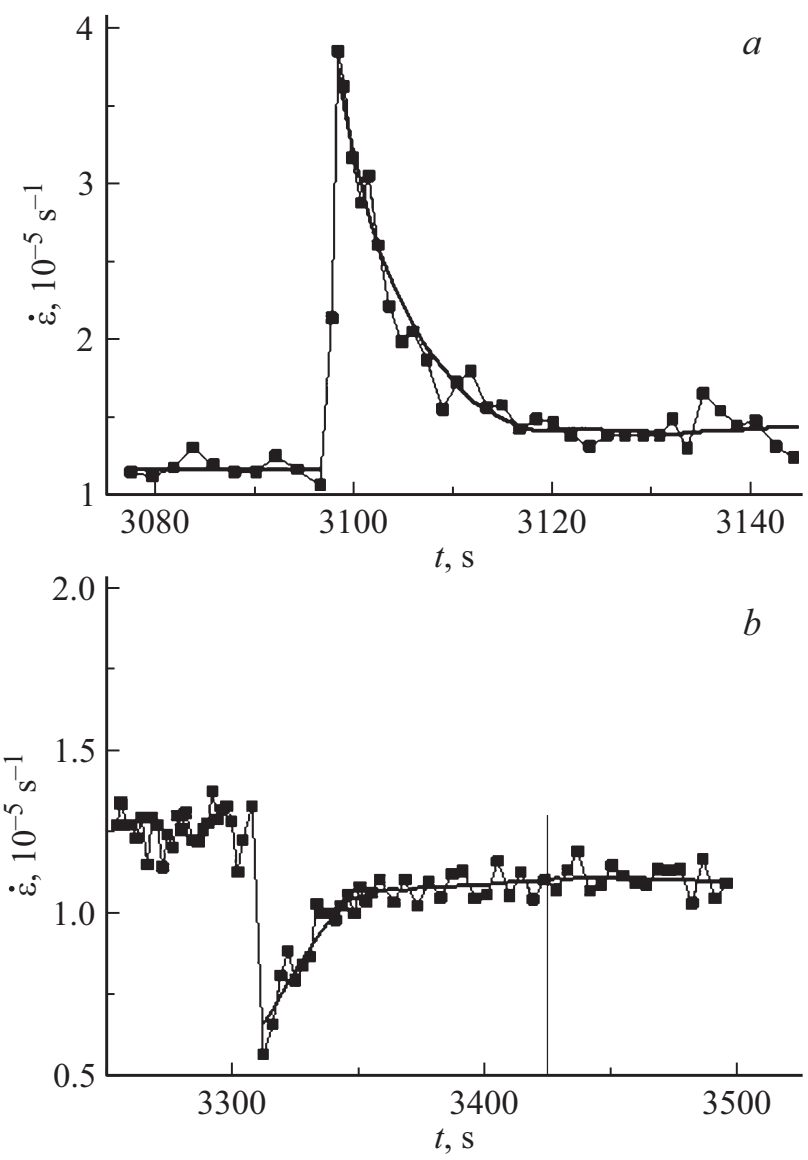

Рис. 2. Зависимость скорости деформации от времени при введении ПМП $(a)$ и его выведении $(b)$. Вертикальной чертой показана условная граница перехода от нестационарного участка деформации к стационарному. 
Характеристики скачков скорости и величины деформации

\begin{tabular}{l|c|c|c|c|c|c}
\hline \multicolumn{1}{c|}{ Параметр } & \multicolumn{3}{|c|}{$0 \mathrm{~T} \rightarrow 0.2 \mathrm{~T}$ (нестац.) $\rightarrow 0.2 \mathrm{~T}$ (стац. $)$} & \multicolumn{3}{|c}{$0.2 \mathrm{~T} \rightarrow 0 \mathrm{~T}$ (нестац. $\rightarrow 0 \mathrm{~T}($ стац.) } \\
\hline$\dot{\varepsilon}, 10^{-5} \mathrm{~s}^{-1}$ & 1.17 & $3.85 \rightarrow 1.42$ & 1.42 & 1.26 & $0.57 \rightarrow 1.11$ & 1.11 \\
$\sigma(\Delta \dot{\varepsilon} / \dot{\varepsilon})$ & 0.067 & 0.074 & 0.057 & 0.059 & 0.062 & - \\
$L, \mu \mathrm{m}$ & $22 ; 150^{*}$ & - & $17 ; 122^{*}$ & $17 ; 122^{*}$ & 0.048 & $22 ; 150^{*}$ \\
$\sigma\left(\Delta U / U_{0}\right)$ & 0.081 & 0.131 & 0.068 & 0.063 & 0.164 & 0.059 \\
$L, \mathrm{~nm}$ & $20-30$ & $10-30$ & $15-25$ & $15-25$ & $10-30$ & $20-30$ \\
& $100-200[23]$ & $50-200$ & $50-150[23]$ & $50-150[23]$ & $50-200$ & $100-200[23]$
\end{tabular}

* Оценка сделана по наибольшим максимумам распределений, приведенным в [23].

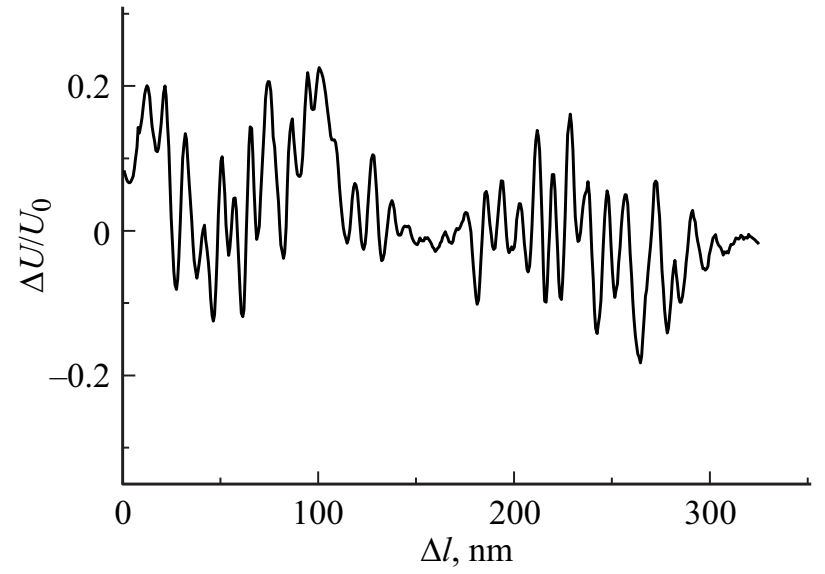

Pис. 3. Относительная величина отклонения сигнала от его расчетной величины $\left(\Delta U / U_{0}\right)$ в зависимости от изменения длины образца $(\Delta l)$ в пределах одного биения на интерферограмме.

участка деформации. Скачок скорости деформации при вводе ПМП больше, а время установления стационарной стадии меньше, чем в обратном процессе. Нами была предпринята попытка сравнить скачки скорости деформации на переходных и стационарных участках деформации. Рассматривалось среднеквадратичное отклонение $\sigma$ величины скачка $\Delta \dot{\varepsilon} / \dot{\varepsilon}$ на заданном отрезке кривой $\dot{\varepsilon}(t)$, где $\Delta \dot{\varepsilon}-$ разница между измеренной скоростью деформации и ее значением на усредненной кривой $[18,23]$. В таблице приведены $\dot{\varepsilon}$ и $\sigma(\Delta \dot{\varepsilon} / \dot{\varepsilon})$ для областей, где скорость деформации близка к постоянной величине (стационарные области), и для участков, следующих за изменением магнитного поля в образце. Из приведенных данных следует, что разброс $\Delta \dot{\varepsilon} / \dot{\varepsilon}$ больше для нестационарных областей, хотя в некоторых случаях величины достаточно близки. Если взять средние значения разброса $\Delta \dot{\varepsilon} / \dot{\varepsilon}$ для всех стационарных и нестационарных участков деформации для описанных выше условий эксперимента, то получим разброс $\Delta \dot{\varepsilon} / \dot{\varepsilon}$, равный 0.058 и 0.068 соответственно.

Что касается размеров микрометровых скачков на нестационарном участке деформации, то корректно определить их невозможно из-за малой деформации, которая составляла $\sim 8 \mu \mathrm{m}$ как при переходе в ПМП, так и при возврате в деформацию без поля. Для стационарных участков деформации свинца в ПМП и вне его они определены в [23], где построены распределения размеров скачков и их изменение при деформации в ПМП, в настоящей работе приведены наиболее вероятные значения (см. таблицу).

Анализ наноразмерных скачков на нестационарных участках проводился на основе измерения отклонения формы биений на интерферограмме $\Delta U$ от стандартной синусоиды, нормированного на ее амплитуду $U_{0}$ [23]. Пример зависимости $\Delta U / U_{0}$ от изменения длины образца $\Delta l$ в пределах одного биения на интерферограмме для области, показанной в правой части рис. 1 и на рис. $2, a$, приведен на рис. 3. Можно заметить один большой скачок размером $L \sim 150 \mathrm{~nm}$ и несколько малых скачков размером 10-20 nm.

Оценки размеров нанометровых скачков, сделанные по нескольким биениям из разных областей деформации на стационарных и нестационарных участках деформации, и среднеквадратичные отклонения от усредненных значений скорости деформации для каждого из них приведены в таблице. Полученные данные показывают, что размеры нанометровых скачков деформации в нестационарной области близки к измеренным в стационарной области при деформации в ПМП и вне его, но область изменения размеров шире, чем при стационарной деформации. Среднеквадратичное отклонение скорости, определенное в области нанометровых скачков для $\Delta U / U_{0}$, ведет себя так же, как аналогичная характеристика в микрометровой области для $\Delta \dot{\varepsilon} / \dot{\varepsilon}$ : в нестационарной области оно наиболее высокое (по сравнению с измеренной в стационарной области) как при деформации в ПМП, так и без него.

Таким образом, при переходе к деформации в ПМП и при прекращении действия ПМП в течение некоторого времени деформация носит нестационарный характер. Этот участок характеризуется резким изменением скорости деформации, увеличением амплитуды скачков скорости деформации, а также расширением области размеров скачков деформации в нанометровом диапазоне. В опытах с постоянными напряжениями по завершении этого участка устанавливается постоянная или зависящая от времени скорость деформации с характерными для деформации в ПМП или без него 
значениями скорости и величины скачков деформации. При длительной деформации свинца в ПМП и без него в областях стационарной деформации магнитное поле приводит к уменьшению амплитуды скачков деформации как в микро-, так и в нанометровом диапазоне и небольшому росту скорости. Наличие нестационарного участка деформации может свидетельствовать о том, что вход или выход поля дает некий толчок структуре, которая затем медленно подстраивается под новые условия. В этом, возможно, заключается противоречие между малыми временами взаимодействия магнитного поля с электронной системой диамагнетика и длительным последействием данного процесса. Какие точечные дефекты ответственны за МПЭ в обычных металлах и сплавах, в настоящее время неизвестно. Обычно используемое объяснение МПЭ, связывающее его с изменением барьеров для движения дислокаций, к сожалению, не конкретизирует физическую природу самого барьера и не позволяет определить, какие элементы его структуры взаимодействуют с магнитным полем.

В заключение следует заметить, что результаты настоящей работы приводят к выводу, что чередование включения и выключения поля может постоянно сохранять нестационарное состояние структуры и тем самым увеличивать скорость деформации или уменьшать силу сопротивления деформации при сохранении величины ее скорости. Это подтвердилось в наших экспериментах при небольшом числе циклов включения-выключения поля. Аналогичный эффект наблюдался нами ранее при деформации высокотемпературного сверхпроводника системы $\mathrm{Y}-\mathrm{Ba}-\mathrm{Cu}-\mathrm{O}$ при $77 \mathrm{~K}$ при одновременном действии нагрузки, электрического тока и магнитного поля [24]. Величина тока и индукция магнитного поля подбирались таким образом, чтобы небольшое изменение того или другого приводило к разрушению сверхпроводящего состояния (переход $S \rightarrow N$ ). Изменение скорости микродеформации при переходе $S \rightarrow N$ и обратном переходе $N \rightarrow S$ было подобно показанному в настоящей работе, но со значительно меньшим временем нестационарного участка. Чередование нескольких прямых и обратных переходов приводило к устойчивому увеличению скорости микродеформации, что позволяло провести аналогию с действием циклической нагрузки на образец, т. е. своеобразной „усталостью“ материала.

\section{Конфликт интересов}

Автор заявляет, что у него нет конфликта интересов.

\section{Список литературы}

[1] Альшии В.И., Даринская Е.В., Перекалина Т.М., Урусовская A.A. // ФТТ. 1987. Т. 29. В. 2. С. 467-470.

[2] Alshits V.I., Darinskaya E.V., Koldaeva M.V., Petrzhik E.A. Magnetoplastic effect in nonmagnetic crystals // Dislocations in solids / Ed. J.P. Hirth. Amsterdam: Elsevier, 2008. V. 14. P. $333-437$.
[3] Головин Ю.И. // ФТТ. 2004. Т. 46. В. 5. С. 769-803.

[4] Моргунов Р.Б. // УФН. 2004. Т. 174. № 2. С. 131-153.

[5] Альшич В.И., Даринская Е.В., Колдаева М.В., Петржсик Е.А. // Письма в ЖЭТФ. 2016. Т. 104. В. 5. C. $362-373$.

[6] Васильев М.A. // Успехи физики металлов. 2007. Т. 8. В. 1. C. $65-105$.

[7] Molotskii M.I. // Mater. Sci. Eng. A. 2000. V. 287. N 2. P. 248-258.

[8] Альшии, В.А., Урусовская А.А., Смирнов А.Е., Беккауер H.H. // ФТТ. 2000. Т. 42. В. 2. С. 270-272.

[9] Альшии, В.И., Даринская Е.В., Колдаева М.В., Котовский Р.К., Петржск Е.А., Трончик П. // УФН. 2017. Т. 187. № 3. С. 327-341.

[10] Дунин-Барковский Л.Р., Моргунов Р.Б., Tanimoto Y. // ФТТ. 2005. T. 47. В. 7. С. $1241-1246$.

[11] Галусташвили М.В., Дрияев Д.Г., Квачадзе В.Г. // Письма в ЖЭТФ. 2019. Т. 110. В. 12. С. 793-796.

[12] Даринская Е.В., Колдаева М.В., Альшии В.И., Волошин А.Э., Притула И.М. // Письма в ЖЭТФ. 2019. Т. 110. B. 4. C. $255-259$.

[13] Даринская Е.В., Колдаева М.В., Альшич В.И., Притула И.М., Волошин А.Э. // Письма в ЖЭТФ. 2018. 108. В. 4. С. $236-242$.

[14] Делюсто Л.Г. Основы прокатки металлов в постоянных магнитных полях. М.: Машиностроение, 2005. 272 с.

[15] Малыгин Б.В. Магнитное упрочение инструмента и деталей машин. М.: Машиностроение, 1989. 112 с.

[16] Краев М.В., Краева В.С. Поглощение сталями энергии деформации в постоянном магнитном поле // XXIII Петербургские чтения по проблемам прочности, посвященные 100-летию ФТИ и 110-летию А.В. Степанова. Сб. материалов. СПб.: Изд-во ВВМ, 2018. С. 348.

[17] Песчанская Н.Н., Пугачев Г.С., Якушев П.Н. // Механика полимеров. 1977. № 2. С. 357-358.

[18] Шиейзман В.В., Песчанская Н.Н. // ФТТ. 2011. Т. 53. В. 6. C. $1169-1174$.

[19] Песчанская Н.Н., Якушев П.Н., Христова Ю., Топлийска А. // Высокомолекуляр. соединения А. 1993. Т. 35. № 9. C. $1493-1497$.

[20] Песчанская Н.Н., Якушев П.Н., Синани А.Б. // ФТТ. 1998. T. 40. B. 3. С. $681-683$.

[21] Песчанская Н.Н., Смирнов Б.И., Шиейзман В.В. // ФТТ. 2008. T. 50. B. 6. C. $997-1001$.

[22] Песчанская Н.Н., Синани А.Б. // ФТТ. 2008. Т. 50. В. 1. C. $177-181$.

[23] Шиейзман В.В., Якушев П.Н. // ФТТ. 2013. Т. 55. В. 9. C. $1765-1770$.

[24] Shpeizman V.V., Orlova T.S., Peschanskaya N.N., Smirnov B.I. // Physical properties of high temperature superconductors. N.Y.: Nova Sci. Publ., 1992. P. 235. 